\title{
Pressupostos para ler a educação intercultural no Brasil colonial a partir da missão jesuítica
}

\author{
Assumptions to read intercultural education in colonial Brazil from the jesuit \\ mission
}

Fábio Eduardo Cressoni*

Universidade da Integração Internacional da Lusofonia Afro-brasileira (UNILAB), Redenção, CE, Brasil.

\begin{abstract}
RESUMO: Este trabalho apresenta considerações sobre a presença jesuítica na América portuguesa ao longo da primeira metade do século XVI e os processos educativos propostos pelos missionários desta ordem para um grupo específico: o Tupinambá. A partir deste objetivo, tenciona-se questionar alguns pressupostos epistêmicos ligados à história e historiografia da educação brasileira. Nesse sentido, questôes teórico-metodológicas fundamentadas em uma história da educação focalizada nos estudos pós-coloniais, na história cultural e nos estudos interculturais críticos são apresentadas ao leitor. Em seguida, demonstram-se alguns dos pressupostos ligados à constituição da ideia de modernidade europeia e um de seus desdobramentos: a expansão colonial luso-cristã e suas práticas pedagógicas interculturais funcionais aos domínios do Império português. Esta conexão, conforme assinalado, é analisada a partir daquilo que chamamos de a demonização da alma indígena. Toma-se, pois, esse itinerário como caminho para valorização da lei 11.645/2008, que estabelece o reconhecimento e a valorização da história e cultura afro-brasileira e indígena, a partir da escrita de uma nova história da educação.
\end{abstract}

PALAVRAS-CHAVE: História da educação. Modernidade. Educação Intercultural. Jesuítas. Tupinambá.

ABSTRACT: This work presents considerations on the Jesuit presence in Portuguese America during the first half of the $1^{\text {th }}$ century and the educational processes proposed by the missionaries of this order for a specific group: the Tupinambá. From this objective, we intend to question some epistemic assumptions related to the history and historiography of Brazilian education. In this sense, theoretical-methodological questions based on a history of education focused on postcolonial studies, cultural history and critical intercultural studies are presented to the reader. Next, some of the assumptions related to the constitution of the idea of European modernity and one of its ramifications are shown: the Luso-Christian colonial expansion and its functional intercultural pedagogical practices in the domains of the Portuguese Empire. This connection, as pointed out, is analyzed from what we call the demonization of the indigenous soul. This itinerary is therefore taken as a way to valorise Law 11.645 / 2008, which establishes the recognition and appreciation of Afro-Brazilian and indigenous history and culture, based on the writing of a new history of education.

KEYWORDS: History of education. Modernity. Intercultural Education. Jesuits. Tupinambá.

\footnotetext{
* Professor da Universidade da Integração Internacional da Lusofonia Afro-brasileira (UNILAB). Doutor em História pela Universidade Estadual Paulista Júlio de Mesquita Filho. E-mail: cressoni@unilab.edu.br. https://orcid.org/0000-0002-1837-2182.
} 


\section{Introdução}

A escrita deste texto deriva de outras reflexões anteriormente propostas por nós acerca da história de nossa primeira educação, isto é, dos processos de ensino-aprendizagem desenvolvidos diante da formação da sociedade brasileira no século XVI. A este recorte espacial e temporal soma-se a opção por historiar a educação de parte das populações indígenas aqui residentes.

É importante salientar que essas opções se fundamentam em inquietações que não partem apenas da apreensão interpretativa de nossa experiência educativa colonial. Como ensina-nos Marc Bloch (2001) $)^{1}$, trata-se de um movimento inverso, cujo ponto de partida para formulação de um questionamento a ser historiado nasce do presente.

A experiência temporal atual dimensiona-nos às lutas dos movimentos indígenas e negros de nosso país que, como demonstram Luís Alberto Oliveira Gonçalves e Petronilha Beatriz Gonçalves e Silva (2003), fundamentam-se nos protestos de rua em direção à formulação de propostas e o estabelecimento de políticas públicas focadas no reconhecimento e na valorização das diferenças como aspecto principal para constituição de uma política de identidade pautada pela relação entre equidade, diversidade, justiça social e igualdade (HALL, 2003; BHABHA, 1998).

Nossa atenção à educação das populações indígenas, na gênese de nossa sociedade, dar-se-á em função de um mecanismo reverso, ou seja, de nosso direcionamento social, político, ético e epistêmico, capaz de reconhecer o problema estrutural-colonial-racial (WALSH, 2009) relativo à formação das sociedades latino-americanas e caribenhas, bem como sua relação com nossa atual experiência histórica. ${ }^{2}$

A efetivação de lutas históricas dos movimentos negros e indígenas, por meio das leis federais 10.639/2003 e 11.645/2008, que alteram elementos relativos à nossa Lei de Diretrizes e Bases (lei federal 9.394/1996), direciona-nos a pensar na história da educação como um vetor para defender, em um campo de disputa simbólica e concreta, políticas públicas de acesso e permanência dessas populações a bens e serviços públicos e privados, por meio de diferentes açóes afirmativas implantadas ou ainda advogadas em nossa sociedade, em defesa de uma educação para as relações étnico-raciais que viabilize as demandas de diferentes sujeitos coletivos e movimentos sociais (HALL, 2006). Entendemos que esse engajamento deve garantir visibilidade, reconhecimento e respeito em relação às suas diferenças (DERRIDA, 1967), bem como a efetivação das medidas específicas, estabelecidas a partir dos diferentes documentos que norteiam e instruem o desenvolvimento de políticas educacionais destinadas à educação das relações étnico-raciais em nosso país.

Nesse sentido, procuraremos demonstrar os fundamentos dos processos de educação intercultural desenvolvidos no Brasil colonial no que tange às populações indígenas. Para tanto, utilizar-nos-emos do exemplo da sociedade Tupinambá. Pretendemos apontar como os processos catequético-educativos implantados pela Companhia de Jesus na América portuguesa, a partir dos contatos interétnicos estabelecidos com as populaçóes autóctones que aqui viviam, produziram um conjunto de narrativas sobre o Outro, fundamentadas na produção de alteridades ligadas à experiência intercultural funcional do Estado português moderno. 


\section{Pressupostos epistêmicos e metodológicos sobre a modernidade europeia, o Império Português e a universalização da Missão Jesuítica}

Partimos da noção de dupla reprodução colonial proposta por Michel de Certeau (1982) para, na sequência, a partir das ideias de alteridade desenvolvidas por Paula Montero (2006), Cristina Pompa (2003) e Adone Agnolin (2005; 2007), observarmos o trabalho de desconstrução e reconstrução dos códigos comunicativos relativos ao processo catequético-educativo interétnico e intercultural missionário moderno (GASBARRO, 2006). Este exercício dar-se-á com base daquilo que Montero (2006) convencionou designar como teoria da mediação cultural, isto é, o estabelecimento de uma investigação que privilegie as práticas simbólicas utilizadas pelos inacianos na tentativa de educar o Outro.

Essa tentativa fundamenta-se na concepção paulina do universalismo cristão, reatualizado, conforme demonstra Enrique Dussel (2000), pela invenção da modernidade e do eurocentrismo, geradores das diferenças coloniais (MIGNOLO, 2003). De acordo com Montero (2006), a gramática religiosa foi o principal código comunicativo pelo qual o Ocidente leu e criou sua representação sobre o Outro ou, melhor dizendo, sobre Seu Outro. Criticar os enunciados decorrentes deste processo educativo nos permite pensar em uma história da educação colonial constituída a partir de novas perspectivas, disposta a repensar as narrativas mestras, consolidadas em torno do eurocentrismo, do evolucionismo e do protagonismo colonizador diante dos demais grupos étnicos e culturais que coabitaram a América portuguesa.

A compressão desse jogo de alteridades relativo à educação intercultural missionária conduz-nos a pensar em algumas das categorias propostas por François Hartog (1999) para analisar as representações das diferenças, entre elas, as ideias de injunção narrativa, desvio sistemático, tradução e inversão, que fundamentaram as práticas pedagógicas inacianas luso-americanas. Desta operação, resultará a comparação, aferida por quatro símiles específicos, enumerados da seguinte forma, a saber: similitudo per contrarium, similitudo per negationem, similitudo per brevitatem e similitudo per collationem.

Compreender como estes paralelos são constituídos, a partir daquilo que Hartog (1999) define como visão analógica projetada em torno da realidade, é um dos elementos aqui propostos. É o entendimento destes processos ligados à lógica educativa intercultural funcional portuguesa e jesuítica que permite criticarmos a mediação interposta pelos missionários nas aldeias e nos aldeamentos, espaços de construção impositiva do pacto de sujeição luso-cristão moderno (HANSEN, 1995).

Neste momento, devemos responder a algumas questôes, entre elas: quem são os integrantes da Companhia de Jesus e quais seus objetivos diante da política do Padroado (BOXER, 1981) adotada em consonância com o Império português? De que maneira as intenções inacianas são postas em prática na América portuguesa? Quais os textos fundadores que orientam estas ações no que diz respeito à forma de ser missionária e sua mediação cultural (MONTERO, 2006; POMPA, 2003)?

Para pensar nessas questóes preliminares, é preciso atentar-se às narrativas que permitem identificar o ethos jesuítico e, por sua vez, seu logos missionário (EISENBERG, 2000; FABRE, 2000; GASBARRO, 2006; O'MALLEY, 2004). Estes elementos, por sua vez, articulam-se à noção de devotio moderna $a^{3}$ (VANDERBROUCKE, 1969; VAUCHEZ, 1995), categoria construída no interior do mito da invenção da modernidade europeia (DUSSEL, 1993). 
Logo, a devotio moderna legitima sua expansão em direção aos continentes africano, asiático e americano e, no caso português, explica a relação intercultural funcional ${ }^{4}$ (WALSH, 2009; TUBINO, 2005) desse Estado na formulação de uma colonialidade do ser que se expressa pela tentativa de colonialidade do saber e do poder (QUIJANO, 2000) relativa à nossa formação histórica.

Os chamados textos fundadores da identidade jesuítica - os Exercicios Espirituais e as Constituiçóes $^{5}$ - devem ser estudados, para podermos compreender a estrutura de pensamento que fundamenta, dimensiona e, sobretudo, permite dinamizar as ações executadas nas missóes que focam outras espacialidades, isto é, no caso americano, aldeias, aldeamentos e engenhos de cana-de-açúcar. Esta observação já fora feita antes por outros pesquisadores, como Michel de Certeau (1982) e Charlotte Castelnau-L'Estoile (2009), que, ao estudar os processos de missionação desenvolvidos na América portuguesa entre os séculos XVI e XVII, indicam a necessidade do historiador se ater às categorias que balizam os sentidos da missão ad majorem Dei gloriam.

Constitui-se, logo, uma hifologia (BARTHES, 2010) do discurso missionário, articulando-o ao estudo de outras fontes primárias, como as primeiras cartas redigidas por Inácio de Loyola, que nos permite localizar os objetivos, fundamentos e métodos da tentativa de salvar-se a si próprio a partir da irredutível tentativa de se reduzir o Outro a um Semelhante (HARTOG, 1999; AGNOLIN, 2007).

Nossa ideia é que a ação educacional missionária deve ser pensada a partir de sua identidade pio mercantil (CRESSONI, 2012). Nesse sentido, a identidade jesuítica deve ser compreendida em torno da junção de duas categorias ligadas à experiência missionária moderna: as ideias de piedade e comércio, discordando da concepção militarista da Ordem fundada por Inácio de Loyola.

Ao lado da tentativa de responder a essas questóes, é preciso pensar acerca da formação do Estado português, de sua associação com a Igreja Católica tridentina, por meio da política do Padroado, bem como no processo de constituição do Império português e, consequentemente, das ações educativas desempenhadas na América pelos interlocutores deste projeto de sociedade, representado pela ideia de Orbis Christianus quinhentista e seiscentista (HOEFFNER, 1957; PAIVA, 1982).

Para compreender esta concepção de mundo, fundadora e justificadora da experiência moderna ocidental lusitana diante das culturas originárias indígenas e ancestrais afrodiaspóricas, atentamo-nos à história da formação da sociedade portuguesa, tomada aqui como Estado teológico-jurídico-político-mercantil (XAVIER; HESPANHA, 1993; PÉCORA, 1994). O estudo do mito fundador desse Estado, constituído em torno do sonho profético que antecede a Batalha de Ourique (1.138), bem como os desdobramentos da formação e expansão desse Estado diante da ideia de uma aventura ultramar moderna mercantil, mas também intercultural (RAMINELLI, 2001), conduzem-nos à compreensão da pedagogia jesuítica intercultural funcional ao Estado português.

O leitor contemporâneo deve ser conduzido a essa compreensão, a partir das concepções de Providência (PAIVA, 2012), ordem, hierarquia, subordinação, disciplina e, por fim, corpo social (PAIVA, 2012; XAVIER; HESPANHA, 1993), fundamentadas na doutrina epistolar paulina acerca do entendimento da ideia de corpo místico (KANTOROWICZ, 1998), a fim de compreender esta forma mentis e, sequencialmente, distanciar-se da adoção de interpretações pós-iluministas e, portanto, anacrônicas a este Clio.

A partir deste entendimento, podemos compreender os pressupostos interculturais funcionais da pedagogia jesuítica na América portuguesa que, ao desconsiderarem os elementos ligados às ancestralidades e tradições das identidades indígenas e afrodiaspóricas, produzem um jogo de 
alteridades (HARTOG, 1999) desigual, cujas diferenças enunciam classificaçóes e, consequentemente, hierarquizações, fundamentadas em padrões homogeneizantes, na tentativa de reduzir as experiências étnicas, raciais e culturais destes grupos a uma única forma de ser, universalizante.

A partir da junção entre os temas apresentados, o debate teórico-conceitual explicitado e os recortes documentais estabelecidos, delineamos os aspectos que fundamentaram a educação intercultural indígena no Brasil colonial.

Essa tessitura permite pensarmos algumas categorias como a demonização da alma indígena (CRESSONI, 2013), em torno dos ritos e mitos que fundamentam a experiência Tupinambáem especial, no que tange à guerra e seus desdobramentos a partir da ideia de festa, tais como a cauinagem, uso desordenado do corpo e a antropofagia (MÉTRAUX, 1979; FERNANDES, 1963; FERNANDES, 1970).

\section{Educação intercultural funcional e sua relação com o estado moderno português: o exemplo da demonização da alma indígena}

Ao pensarmos no conceito de demonização da alma indígena, no que tange à observação dos processos catequético-educativos desempenhados pela mediação jesuítica em relação à sociedade Tupinambá, procuramos atentar-nos a três aspectos dessa narrativa e sua relação com o pressuposto intercultural funcional ao Estado moderno português. São eles: a introdução à suposta maléfica América, a construção do cenário infernal e do personagem diabólico e, por fim, o combate aos ritos malignos, por meio da ortopraxia jesuítica.

A documentação epistolar jesuítica quinhentista, bem como outras fontes - gramáticas, catecismos, textos teatrais, poemas, dentre outras formas narrativas acerca de Seu Outro - produzidas no contexto da missionação, indicam-nos a América portuguesa como um lócus infernal. Essa representação ocorre pelo temor relativo a um conjunto de práticas exercitadas pelos Tupinambá que são condenáveis na perspectiva da missão.

Nóbrega trata de alguns hábitos condenáveis pela missão - antropofagia, poligamia e guerra - a partir da descrição de um suposto índigena desejoso em mudar de vida:

Diz que quer ser christao e nom comer carne humana, nem ter mais de huma molher e outras cousas; soomente que ha-de ir a guerra e os que cativar vende-los e servir-se delles, porque estes desta terra sempre tem guerra uns com outros e asi andao todos em discordia. Comem-se huns a outros, digo hos contrarios (CARTAS I, 1956, p. 111).

O Diálogo sobre a conversão do gentio (1556-57) segue essa mesma perspectiva. O texto escrito por Nóbrega indica, de maneira sintetizada, as dificuldades enfrentadas pelos missionários, a partir de uma conversa travada por dois colonos. O Outro é tomado para Si Próprio por meio das seguintes condições: animalidade, bestialidade, ausência de crença e, por fim, inconstância:

Gonçalo Alvarez: Por demais hé trabalhar com estes; são tão bestiais, que não lhes entra no coração cousa de Deus; estão tão encarniçados em matar e comer, que nenhuma outra bem-aventurança sabem desejar; pregar a estes, hé pregar em deserto há pedras. 
Matheus Nogueira: Se tiveram rei, poderão-se converter, ou se adoram alguma cousa; mas, como nam sabem que cousa crer nem adorar, não podem entender há pregação do Evangelho, pois ella se funda em fazer crer e adorar a hum soo Deus, e a esse só servir; e como este gentio nam adora nada, sem cree nada, todo o que lhe dizeis se fique nada (1956, p. 320).

A sequência do texto trata da dificuldade da inserção da fé cristã, seguindo os princípios da racionalidade pio mercantil própria da Companhia de Jesus. Antes, a contabilidade inaciana indicava a conversão de todos os brasis em apenas uma hora. Entretanto, as dificuldades elencadas inverteriam esse cenário: os missionários perceberiam que não poderiam converter tampouco apenas um único índio ao longo de um ano.

É preciso decifrar o Outro. Dessa forma, Nóbrega segue seu diálogo imaginário através de uma narrativa fundamentada em um esquema de comparação. Estabelecendo uma analogia linguística, considerando o idioma nativo e as sagradas escrituras, o missionário gera uma teia simbólica que, a princípio, permite uma aproximação para, em seguida, realizar a transferência dos sentidos dados à forma de ser Tupinambá.

A inconstância é justificada em função de uma interpretação dos advérbios indígenas que nega o léxico do Outro, transformando-o em diferente e, portanto, vazio. A tudo os Tupinambá dizem $p \hat{a}$ (sim), afirma Nóbrega, na mesma proporção que dizem aani (não). Dessa maneira, disposto a transferir sua aproximação para seus semelhantes (ante oculos ponere), Nóbrega traçaria um paralelo exegético, utilizando um trecho do evangelho de Mateus, em função da ortopraxia desempenhada na América.

O fragmento selecionado informa-nos acerca de um homem que possuía dois filhos: solicitando que um deles seguisse para uma vinha, a fim de trabalhar, ele respondeu ao pai que não iria cumprir com esta solicitação. Todavia, arrependido, este seguiu a ordem do pai. Na sequência, o pai fez o mesmo pedido ao segundo filho. Prontamente, este afirmou que cumpriria sua determinação. Entretanto, ele não foi para a vinha (Mat. 21, 28-30). Os índios, na percepção de Nóbrega, estavam a agir como o segundo filho, divergindo da vontade de Deus.

Encontramos nesse trecho os quatro símiles acentuados por Hartog (1999) em seu esquema de comparação: similitudo per contrarium, similitudo per negationem, similitudo per brevitatem e similitudo per collationem. O Outro é identificado a partir de um elemento contrário (a inconstância) à forma de ser luso-cristã, para, em seguida, ser negado e descrito em conformidade com uma projeção do real identificada com o universalismo que fundamenta as ações jesuíticas, reduzindo o diferente, analogicamente, por meio de uma aproximação que o classifica hierarquicamente como inferior, em comparação com outros grupos.

Este processo se seguirá na comparação dos Tupinambá com outros grupos (romanos, gregos, judeus e mouros). Toda inconstância dos indígenas, base dos maus costumes, tal qual se deu com outros grupos que entraram em contato com o cristianismo, teria ocorrido em função de erros que tornaram esses povos cegos, ou seja, incapazes de aceitarem a verdade revelada pela única fé possível, conforme a projeção universalizante das reduções inacianas. A diferença nessa passagem do trecho do Diálogo, que afirma os índios “[...] dão credito a hum feiticeiro que lhes põe a bem-aventurança na vingança de seus inimigos e na valentia, e em terem muitas mulheres” (NÓBREGA, 1956, p. 336), é ressaltada por dois pontos. Primeiro: o autor identifica o responsável pela inconstância e, consequentemente, pelos maus costumes (feiticeiro). Segundo: o autor liga os erros (maus costumes) à cegueira (inconstância) e, por fim, à mentira (expressa no crédito dado ao Outro - feiticeiro), cuja origem é condicionada a um saber compartilhado entre os participantes da colonização da América portuguesa. 
Articulado ao espaço de sua produção e difusão, esse saber permitirá a associação com a figura do Demônio como hipótese para a compreensão da forma de ser ameríndia, pois, como afirma um dos personagens de Nóbrega, a justificativa para o entendimento desse processo se daria pelo reconhecimento da presença do pai da mentira (Diabo), reinstalado em novas terras. ${ }^{6}$ Esse redirecionamento permitirá a configuração de um novo cenário (inferno), acrescido de um novo personagem (Diabo), fundamentado na presença dos caraíbas nas aldeias e nos aldeamentos jesuíticos.

Esse redimensionamento transformou o caraíba em uma metonímia americana do Diabo europeu. Em carta aos padres e irmãos de Coimbra (1551), António Pires afirmaria que a população indígena dava pouco crédito à ação missionária. As dificuldades são expressas em função da presença ativa do Demônio, que se assentara na América por meio dos caraíbas, considerados "legos ministros de Satanás” (CARTAS I, 1956, p. 253). Postos em peregrinação, os jesuítas deparavam-se com a constante necessidade de corrigir os maus costumes indígenas (su faltas) e seus operadores (bechizeros), "mostrándoles sus engaños muy claros [...] porque le hablavan del inferno y del diablo" (Idem, Ibidem, p. 378). Em outra carta, os missionários informavam que os Tupinambá permitiam que os caraíbas homens que "[...] dizen muchas cosas falsas y mentiras que el demonio, su padre, les enseña” (Idem, Ibidem, p. 384), acessasem suas aldeias.

O caraíba, concebido dessa forma pela missão, negava os códigos da linguagem religiosa-jurídico-mercantil luso-cristã exercida na América. Nesse sentido, Pompa pontua que:

[...] eles negam os princípios da vida social porque negam a troca: linguística (são silenciosos, ou cantam), social (são solitários, ou polígamos, mulheres virgens preparam suas comidas), alimentar (não produzem, recebem bens em excesso). Não vivem nas comunidades, vão e vêm de aldeia em aldeia, são errantes, vagabundos, perigosos porque mediadores entre duas esferas que não deveriam estar em contato: humana e divindades [...] (2003, p. 173).

Os maus costumes, dados não mais pela ideia inicial dos papéis em branco descritos por Nóbrega, são redefinidos em função de uma teia simbólica que adjetivou o caraíba como responsável pela cegueira Tupinambá, fundamentada na ilusão e na falsidade dos feiticeiros descritos pela Companhia de Jesus. Nesse sentido, pondera Agnolin, a presença jesuítica trabalharia a fim de reordenar o novo espaço, procurando redimensioná-lo em consonância com os preceitos propostos pela missão:

Os excessos indígenas identificavam-se, sobretudo, com o conjunto de 'costumes abomináveis' ou 'maus costumes' - cauinagem, guerra, antropofagia, sexualidade desordenada, pinturas, danças, etc. - que conotava um estágio (de memória aristotélica) inferior de humanidade, revelador de uma profunda desordem social e que dificultava, ao mesmo tempo, o processo de civilização, fundamento irrenunciável para a (posterior) obra de cristianização. No combate a esses institutos, assim como à instituição central da cultura tupi do karaíba, os 'redutores' jesuítas, serão sempre irredutíveis (2007, p. 276, grifos do autor).

Dessa forma, os missionários identificaram os caraíbas como principais adversários da expansão luso-cristã na América. Raminelli, ao estudar as representações iconográficas pertinentes aos índios na América portuguesa no decorrer do período colonial, constatou a associação entre esses personagens e o Diabo nas descrições da ortopraxia inaciana: 
Os pajés, por sua vez, constituíram o mais forte elo entre os índios e os demônios. Os caraíbas eram os servidores do Diabo, não permaneciam na aldeia e recusavam-se ao convívio diário com a tribo. Viviam nas florestas e mantinham contatos com os espíritos. E assim procuravam disfarçar sua malignidade e destacar-se entre os moradores da aldeia (1996, p. 121).

Essa associação é estabelecida por outros autores. Pompa indica que os jesuítas entendiam que os caraíbas "[...] se opóem com toda a sua força e poder diabólico ao grande desenho catequético de marca escatológica, vale dizer, à realização do grandioso projeto do Reino de Deus na Terra, com o genus angelicum dos índios” (2001, p. 186), sendo que, para esta mesma autora, na ausência "[...] de outros sinais de idolatria, são estes extraordinários personagens, dos quais as fontes não ignoram nem minimizam o poder, os intermediários entre o Diabo e as almas selvagens” (Idem, Ibidem, grifos do autor).

\section{Considerações finais ou pressupostos para ler a educação intercultural ligada ao estado moderno português e à missão jesuítica}

Procuramos indicar alguns pressupostos para compreendermos os processos catequético-educativos ligados à nossa primeira experiência educacional, aqui exercitada pelos missionários da Companhia de Jesus. As opções teórico-metodológicas apresentadas no decorrer deste texto visaram a demonstrar a necessidade de outra escrita sobre a história da educação brasileira relativa ao período colonial, em especial no que compete aos processos interétnicos e interculturais.

O processo da ideia emergencial de uma (re)leitura desse recorte temporal, espacial e temático justifica-se em função das políticas públicas enunciadas logo na introdução deste texto, isto é, ações focadas no desenvolvimento de uma educação para as relações étnico-raciais em nosso país. Dessa maneira, somam-se à historiografia clássica, eurocentrada, elementos oriundos de outras epistemes, ou seja, categoriais advindas dos estudos pós-coloniais e interculturais.

O exemplo constituído em torno da ideia de demonização da alma indigena, fundamentado na mediação cultural interposta pela missão, buscou apresentar o problema da interculturalidade funcional ao Estado moderno português por meio dos processos de ensino-aprendizagem implementados nas aldeias e nos aldeamentos inacianos.

Dessa forma, esperamos poder contribuir para o despertar de novas pesquisas, dispostas a dialogar a partir de novas perspectivas e, por consequência, inquietações fundamentadas na constituição de uma sociedade mais equídea sob o ponto de vista étnico-racial, em especial no que diz respeito às demandas dos sujeitos coletivos e movimentos sociais historicamente tratados de forma desigual em nosso país, em especial às populações indígenas e negras aqui residentes.

\section{Referências}

AGNOLIN, Adone. Jesuítas e Selvagens. A negociação da fé no encontro catequético-ritual americano-tupi (sec. XVI-XVII). São Paulo: Humanitas Editorial, 2007.

AGNOLIN, Adone. O Apetite da Antropologia. O sabor antropofágico do saber antropológico: alteridade e identidade no caso tupinambá. São Paulo: Humanitas, 2005. 
BHABHA, Homi K. O local da cultura. Belo Horizonte: EdUFMG, 1998.

BLOCH, Marc. Apologia da história. Rio de Janeiro: Jorge Zahar, 2001.

BOXER, Charles. A Igreja e a expansão ibérica (1440-1700). Lisboa: Edições 70, 1981.

CARTAS JESUÍTICAS (1549-1594). Belo Horizonte: Itatiaia; São Paulo: Edusp, 1988. 3 vols.

CASTELNAU-L'ESTOILE, Charlotte de. Operários de uma vinha estéril. Os jesuítas e a conversão dos índios no Brasil: 1580-1620. Tradução de Ilka Stern Cohen. Bauru: EdUSC, 2006.

CERTEAU, Michel de. A escrita da história. Tradução de Maria de Lourdes Menezes. Rio de Janeiro: Forense Universitária, 1982.

CRESSONI, Fábio Eduardo. Os Exercícios Espirituais e a construção da identidade pio mercantil jesuítica. In: CRESSONI, Fábio Eduardo (Org.). Educação, sociedade e cultura na América portuguesa. Estudos sobre a presença jesuítica. Curitiba: CRV, 2012. p. 16-38.

DERRIDA, Jacques. L'écriture et la différence. Paris: Seuil, 1967.

DUSSEL, Enrique. 1492, o encobrimento do outro. A origem do mito da modernidade. Petrópolis: Vozes, 1993.

DUSSEL, Enrique. Europa, modernidad y eurocentrismo. In: LANDER, Edgardo (Org.). La colonialidad del saber: eurocentrismo y ciencias sociales, perspectivas latino-americanas. Buenos Aires: Clacso, 2000.

EISENBERG, Jose. As missões jesuíticas e o pensamento político moderno: encontros culturais, aventuras teóricas. Belo Horizonte: Ed. UFMG, 2000.

FABRE, Pierre-Antonie. Ils iront em pèlerinage... L' “expérience” du pèlerinage selon l' “Examen général” dês Constitutions de la Compagnie de Jésus et selon les pratiques contemporaines. In: BOUTRY, Philippe; FABRE, Pierre-Antoine; JULIA, Dominique. Rendre ses voeux. Les identites pelerines dans I'Europe moderne (XVIXVIII siecles). Paris: Editions de l'Ecole des Hautes Etudes en Sciences Sociales, 2000. p. 159-188.

FERNANDES, Florestan. A função social da guerra na sociedade Tupinambá. 2. ed. São Paulo: EDUSP, 1970. FERNANDES, Florestan. Organização social dos Tupinambá. São Paulo: Difusão Europeia do Livro, 1963.

GASBARRO, Nicola. Missões: a civilização cristã em ação. In: MONTERO, Paula (Org.). Deus na aldeia: missionários, índios e mediação cultural. São Paulo: Globo, 2006. p. 67-109.

HALL, Stuart. Da Diáspora. Identidades e mediações culturais. Belo Horizonte: EdUFMG, 2003.

HALL, Stuart. A identidade cultural na pós-modernidade. Tradução de Tomaz Tadeu da Silva e Guacira Lopes Louro. Rio de Janeiro: DP\&A Editora, 2006.

HANSEN, João Adolfo. O nu e a luz: cartas jesuíticas do Brasil. Nóbrega: 1549-1558. Revista do Instituto de Estudos Brasileiros, São Paulo, n. 38, 1995. p. 87-119.

HARTOG, Francois. O espelho de Heródoto: ensaio sobre a representação do outro. Tradução de Jacyntho Lins Brandao. Belo Horizonte: EdUFMG, 1999.

HERNANDES, Paulo Romualdo. Os exercícios espirituais e o teatro. In: PAIVA, José Maria de; BITTAR, Marisa; ASSUNCAO, Paulo de (Orgs.). Educação, história e cultura no Brasil Colônia. São Paulo: Arke, 2007. p. 59-72.

HOEFFNER, Joseph. La ética colonial española del siglo del oro. Madri: Cultura Hispânica, 1957.

JANSEN, T. Devotio Moderna [verbete]. In: Lexicon. Dicionário teológico enciclopédico [Dizionario teologico enciclopedico]. São Paulo: Loyola, 2003. p. 191- 192.

KANTOROWICZ, Ernest H. Os dois corpos do rei: um estudo sobre teologia política medieval. São Paulo: Companhia das Letras, 1998.

METRAUX, Alfred. A religião dos Tupinambás e suas relações com as demais tribos tupi-guarani. 2. ed. São Paulo: Nacional: Edusp, 1979.

MIGNOLO, Walter D. Histórias locais, projetos globais. Belo Horizonte: EdUFMG, 2003.

MONTERO, Paula. Índios e missionários no Brasil: para uma teoria da mediação cultural. In: MONTERO, Paula (Org.). Deus na aldeia: missionários, índios e mediação cultural. São Paulo: Globo, 2006. p. 31-66. 
NÓBREGA, Manoel da. Diálogo sobre a conversão do gentio [1556-57]. In: Cartas dos primeiros jesuítas do Brasil. vol. II. LEITE, Serafim (org.). São Paulo: Comissão do quarto centenário da cidade de São Paulo, 1956. p. 317-345.

O’MALLEY, John W. Os primeiros jesuítas. Tradução de Domingos Armando Donida. São Leopoldo: Ed. Unisinos; Bauru: EdUSC, 2004.

PAIVA, Jose Maria de. Colonização e Catequese (1549-1600). São Paulo: Autores Associados: Cortez, 1982.

PAIVA, Jose Maria de. Religiosidade e cultura brasileira: séculos XVI-XVII. Maringá: EDUEM, 2012.

PÉCORA, Alcir. Teatro do sacramento. A unidade teológico-retórico-política dos sermões de Antonio Vieira. São Paulo: Edusp; Campinas: Unicamp, 1994.

POMPA, Cristina. Profetas e santidades selvagens. Missionários e caraíbas no Brasil colonial. Revista Brasileira de História, v. 21, n. 40, 2001.

POMPA, Cristina. Religião como Tradução: missionários, Tupi e Tapuia no Brasil colonial. Bauru: EdUSC, 2003.

QUIJANO, Aníbal. La colonialidad del saber: eurocentrismo y ciencias sociales. Perspectivas latinoamericanas. Buenos Aires: Clacso, 2000.

RAMINELLI, Ronald. Imagens da Colonização. A representação do índio de Caminha a Vieira. São Paulo: Edusp: Fapesp; Rio de Janeiro: Jorge Zahar, 1996.

SILVA, Petronilha Beatriz Gonçalves e; GONÇALVES, Luis Alberto Oliveira. Multiculturalismo e educação: do protesto de rua a propostas e políticas. Educação e Pesquisa. São Paulo. v. 29, n. 1, p. 109-123, jan./jun. 2003.

TUBINO, Fidel. La interculturalidad crítica como proyecto ético-político. In: Encuentro continental de educadores agustinos. Lima, 24-28 de enero de 2005. Disponível em: http://oala.villanova.edu/congresos/educación/ lima-ponen-02.html. Acesso em: 09. dez. 2015.

VANDENBROUCKE, Francois. Spiritualitá del Medioevo. Nuovi ambienti e nuovi problemi (sec. XII-XVI) [La Spiritualite du Moyen Age] Bologna: Edizioni Dehoniane, 1969.

VAUCHEZ, Andre. A espiritualidade na Idade Média Ocidental. Séculos VIII a XIII. Tradução de Lucy Magalhães. Rio de Janeiro: Jorge Zahar Editor, 1995.

WALSH, Catarine. Interculturalidad crítica y educación intercultural. Versão ampliada da comunicação apresentada no Seminário “interculturalidad y Educación Intercultural”. Instituto Internacional de Integração Andrés Bello (Org.). La Paz, 09-11 de março de 2009. Disponível em: file:///C:/Users/PESSOAL/Downloads/interculturalidad\%20critica\%20y\%20educacion\%20intercultural\%20(C.\%20WASH).pdf. Acesso em: 09 dez. 2015.

XAVIER, Angela Barreto; HESPANHA, Antonio Manuel. A representação da sociedade e do poder. In: HESPANHA, Antonio Manuel (Org.). História de Portugal. O Antigo Regime (1620-1807). Vol IV. MATTOSO, Jose (Dir.). Lisboa: Estampa, 1993. p. 121-51.

\title{
Notas
}

\begin{abstract}
${ }^{1}$ Afirmará Bloch, “Diz-se algumas vezes: 'A história é ciência do passado'. É falar errado” (2001, p. 52), uma vez que “[...] o passado é, por definição, um dado que nada mais modificará. Mas o conhecimento do passado é uma coisa em progresso, que incessantemente se transforma e se aperfeiçoa" (2001, p. 75).

${ }^{2}$ Fundamentada na ideia de interculturalidade crítica, a concepção de educação intercultural aqui proposta como projeto político-social-ético-epistémico é, de acordo com Walsh (2009), algo a ser construída nos diferentes campos das ciências humanas, entre eles, a história da educação. Nesse sentido, Walsh tratará de afirmar que esta proposta se constitui em uma estratégia, ação e processo permanente de relação e negociação entre diferentes grupos étnicos, raciais e culturais na contemporaneidade. A construção das condições de respeito, legitimidade, equidade, igualdade e simetria poderão dar-se, em nosso entendimento, com contribuições advindas de diferentes campos do saber pedagógico, entre eles, os estudos interétnicos sobre nossa primeira história da educação, uma vez que essa proposta se encontra disposta a discutir mecanismos de desigualdade, inferiorização, racialização e discriminação típicos da experiencial colonial luso-cristã quinhentista e seiscentista, a partir dos pressupostos colocados em prática pelos missionários da Companhia de Jesus, responsáveis pelos processos educativos da Colônia entre os anos de 1549 e 1759.
\end{abstract}

${ }^{3}$ Desenvolvida na Europa, a partir do século XIV, a Devotio moderna é antiespeculativa tanto em termos teológicos quanto devocionais, realçando, a partir de uma nova espiritualidade, ativa, centrada em um cristocentrismo prático, modificações 
na vida interior, conforme informa-nos Jansen: “[...] a humanidade de Cristo e o eixo central em torno do qual se move a vida espiritual, em tom ético e concreto, visando à imitação dos exemplos de Cristo. Em segundo lugar, vem à oração metódica, especialmente o exame de consciência e a meditação. Esta última se transforma no eixo do ascetismo. [...]. Aliás, é inegável uma tendência moralista e antiespeculativa. Aos devotos, o que importa e uma vida virtuosa realmente vivida" (2003, p. 191-92).

${ }^{4}$ A estadunidense radicada no Equador Catarine Walsh (2009) e o filósofo peruano Fidel Tubino (2005), interessados nos estudos sobre a relação entre educação e interculturalidade entre as populações afro-indígenas latino-caribenhas, desenvolvem o conceito de interculturalidade crítica, em contraste às ideias de interculturalidade relacional e funcional. Neste momento, interessa-nos a ideia de que a interculturalidade funcional reconhece a presença da diversidade, isto é, do Outro, aquele que se difere etnicamente, racialmente e culturalmente, nesse caso, da forma de ser portuguesa quinhentista e seiscentista, ou seja, indígenas e negros africanos e afro-brasileiros. No entanto, esse modelo estruturalcolonial-racial racializa os contatos interétnicos estabelecidos entre esses grupos e o Gubernatio Christiano português gestado na América pela Companhia de Jesus. As práticas pedagógicas que fomentam esta lógica encontram-se, pois, ancoradas a este conjunto teológico-jurídico-político-mercantil inerte a esta rede de relações.

${ }^{5}$ Escritos entre os anos de 1521 e 1522, sendo aprovados pouco mais de vinte cinco anos mais tarde, os Exercícios Espirituais exemplificam a concepção europeia cristã de devotio moderna, propondo a seus praticantes experiências próprias do Drama da Salvação (HANSEN, 1995), fazendo da espiritualidade inaciana um combate ativo contra os inimigos de Deus - infiéis, hereges e demônios -, conforme demonstra Paulo Romualdo Hernandes (2007), ao estudar a relação entre esse texto e as peças teatrais escritas por José de Anchieta, encenadas na América portuguesa no decorrer da segunda metade do século XVI. Aprovada no ano de 1539, as Constituições regulam a forma de ser jesuíta, ao tratar de temas próprios das missões, tais como: expansão, uniformidade, adaptabilidade e salvação, além de conter um capítulo específico sobre o conceito de educação adotado por esta Ordem, estabelecendo, portanto, a forma de proceder inaciana diante do Outro.

${ }^{6}$ Nóbrega, narra que “[...] erros com erros, cegueira com cegueira, tudo achareis mentira, que procede do pai da mentira, mentiroso desde o começo do mundo" (1956, p. 336). Sua afirmação é fundamentada em uma passagem do Evangelho de João (8: 44-45), em que Jesus dialoga com um grupo de fariseus. O Outro, desconhecendo a linguagem de Deus, é identificado com o Demônio, opositor da suposta verdade a ser universalizada a partir da missão, conforme podemos observar a partir da leitura do trecho mencionado: “Vós tendes como pai o demônio, e quereis fazer o desejo de vosso pai. Ele era homicida desde o começo e não permaneceu na verdade, porque a verdade não está nele. Quando diz a mentira, fala do que lhe é próprio, porque é mentiroso e pai da mentira. Mas eu, por vos digo a verdade, não me credes” (1986, p. 1396).

Submetido em: 18/12/2019

Aprovado em: 10/04/2020 